Cambridge Institute of Therapeutic Immunology and Infectious Diseases, Department of Medicine, University of Cambridge, Cambridge, UK

slc50@cam.ac.uk

Cite this as: BM/2020;370:m3270 http://dx.doi.org/10.1136/bmj.m3270 Published: 24 August 2020

\title{
Russian SARS-CoV-2 vaccine
}

\author{
Release without phase III trial entails numerous risks \\ Sarah Caddy Wellcome Trust clinical research career development fellow
}

The announcement by Russia's president, Vladimir Putin, that the country has developed and approved the world's first SARS-CoV-2 vaccine ${ }^{1}$ raises many questions. The global scientific community is concerned that this is a high risk move on the part of the Russian government.

The vaccine, named Sputnik V, was developed by the Gamaleya Research Institute of Epidemiology and Microbiology, based in Moscow and supported by the Russian Ministry of Health. It uses an adenovirus vector to deliver the gene for the SARS-CoV-2 spike protein, a similar approach to that being used by the vaccine development team at the University of Oxford and AstraZeneca, albeit with different adenovirus vectors. The Russian vaccine is based on two human adenovirus vectors ( $\mathrm{Ad}_{5}$ and $\mathrm{Ad} 26$ ), whereas the Oxford vaccine uses a chimp vector (ChAdOx).

\section{Concerns}

The main concern is that the Russian vaccine has not yet been through a phase III clinical trial. Such a trial, typically involving over 10 ooo volunteers and comparing the vaccine with placebo, would seek to prove vaccine efficacy as well as safety. Without phase III data we don't know whether the Russian vaccine can protect people from SARS-CoV-2. Claims of efficacy are currently being based on unpublished data from two small phase II trials, descriptions of which are outlined in ClinicalTrials.gov ${ }^{23}$ A website for the vaccine launched by the Russian Direct Investment Fund states that that all 76 volunteers who received it developed high titres of SARS-CoV-2 specific antibodies and good cellular immunity. ${ }^{4}$ However, as it is still unclear what the ideal protective immune response to SARS-CoV-2 is, it is not possible to know whether these people would be protected against covid-19.

Nor is it known whether the vaccine is safe. No "serious complications or side effects" were reported in the phase II trials, ${ }^{1}$ but they included only a small number of healthy participants. More extensive testing has been performed for a similar $\mathrm{Ad}_{5}$ based covid-19 vaccine in Wuhan, where no serious adverse events were documented in 382 healthy volunteers. ${ }^{5}$ But neither vaccine has been tested in people with pre-existing health conditions, who are arguably most in need of protection. Furthermore, there is theoretical concern that vaccine induced SARS-CoV-2 antibodies may have the potential to worsen infection or cause immunopathology, so called antibody dependent enhancement of disease. ${ }^{6}$ Though this risk is now estimated to be low, without extensive testing we cannot accurately predict outcome. The health of people receiving the Russian vaccine will consequently need to be closely monitored.
Any negative effect of the Russian vaccine could extend far beyond the people physically receiving it. An ineffective, or even dangerous, vaccine has the potential to substantially diminish confidence in and uptake of other vaccines that are subsequently approved. A European survey of over 7500 participants found that $19 \%$ of people were unsure they would take a SARS-CoV-2 vaccine, and $7 \%$ said they would refuse vaccination altogether. ${ }^{7}$ A poorly performing vaccination programme in Russia could increase vaccine hesitancy internationally.

\section{Regulatory pathways}

Russia's vaccine has been able to skip phase III clinical trials because of differences in medicine regulatory pathways across the world. Many countries and regions have their own regulatory body-for example, the European Medicines Agency or the Food and Drug Administration in the US. Additionally, the World Health Organization prequalification team provides regulatory guidance to countries without regulatory capacity. ${ }^{8}$ Many of these agencies work closely together, and a recent meeting of the International Coalition of Medicine Regulatory Authorities agreed a set of principles for conducting phase III clinical trials for SARS-CoV-2 vaccines. ${ }^{9}$ Russia's medicine regulatory body, however, acts independently of other agencies, and its decision making processes are not always fully transparent outside of the country

According to WHO guidelines on clinical evaluation of vaccines, ${ }^{10}$ six vaccine candidates are already ahead of the Russian vaccine in the standard development pipeline. These candidates are all in phase III trials in multiple countries. ${ }^{11}$ The trials are expected to take months to complete, and the vaccine candidates are unlikely to be equally effective. Phase III trials are reported to be about to start for the Russian vaccine, but it remains to be seen whether this will affect any regulation and licensing of the vaccine. The Russian vaccine could still be a valuable tool for controlling covid-19, but global scepticism is high and only extensive further studies will tell. Whatever the urgency of the current pandemic situation, there is the possibility that the release of an untested vaccine could wreak long term damage on international efforts to contain covid-19.

Competing interests: The BM/has judged that there are no disqualifying financial ties to commercial companies. The authors declare no other interests. The BMJ policy on financial interests is here: www.bmj.com/sites/default/files/attachments/resources/2016/03/16-current-bmj-education-coi-form.pdf

Provenance and peer review: Commissioned; not externally peer reviewed.

I thank Gordon Dougan for constructive comments.

President of Russia. Meeting with government members. 2020 http://en.kremlin.ru/events/president/news/63877 
2 US National Library of Medicine. 2020. https://ClinicalTrials.gov.

3 US National Library of Medicine. 2020. https://ClinicalTrials.gov

$4 \quad$ Russian Direct Investment Fund. Sputnik V. https://sputnikvaccine.com

5 Zhu FC, Guan XH, Li YH, etal. Immunogenicity and safety of a recombinant adenovirus type-5-vectored COVID-19 vaccine in healthy adults aged 18 years or older: a randomised, double-blind, placebo-controlled, phase 2 trial. Lancet 2020;396:479-88. doi: 10.1016/S0140-6736(20)31605-6 pmid: 32702299

6 Arvin AM, Fink K, Schmid MA, etal. A perspective on potential antibody-dependent enhancement of SARS-CoV-2. Nature2020;584:353-63. doi: 10.1038/s41586-020-2538-8. pmid: 32659783

7 Neumann-Böhme S, Varghese NE, Sabat I, etal. Once we have it, will we use it? A European survey on willingness to be vaccinated against COVID-19. Eur J Health Econ 2020;21:977-82. doi: 10.1007/s10198-020-01208-6 pmid: 32591957

8 WHO Prequalification Team. https://extranet.who.int/prequal/content/overview-history-mission

9 International Coalition of Medicines Regulatory Agencies. ICMRA SARS-CoV-2 vaccines workshop \#2-summary. 2020. http://www.icmra.info/drupal/news/22june2020/summary

10 World Health Organization. Annex 9. Guidelines on clinical evaluation of vaccines: regulatory expectations. 2017. https://www.who.int/biologicals/expert_committee/WHO_TRS_1004_web_Annex_9.pdf

11 World Health Organization. Draft landscape of COVID-19 candidate vaccines-10 August 2020. https://www.who.int/who-documents-detail/draft-landscape-of-covid-19-candidate-vaccines

This article is made freely available for use in accordance with BMJ's website terms and conditions for the duration of the covid-19 pandemic or until otherwise determined by BMJ. You may use, download and print the article for any lawful, non-commercial purpose (including text and data mining) provided that all copyright notices and trade marks are retained. 